\title{
Exploring the symbiont diversity of ancient western redcedars: arbuscular mycorrhizal fungi of long-lived hosts
}

Article

Accepted Version

Gorzelak, M. A., Pickles, B. J. and Hart, M. M. (2017)

Exploring the symbiont diversity of ancient western redcedars: arbuscular mycorrhizal fungi of long-lived hosts. Molecular Ecology, 26 (6). pp. 1586-1597. ISSN 0962-1083 doi: https://doi.org/10.1111/mec.14023 Available at https://centaur.reading.ac.uk/68653/

It is advisable to refer to the publisher's version if you intend to cite from the work. See Guidance on citing.

To link to this article DOI: http://dx.doi.org/10.1111/mec.14023

Publisher: Wiley

Publisher statement: "This is the peer reviewed version of the following article: 'Exploring the symbiont diversity of ancient western redcedars: arbuscular mycorrhizal fungi of long-lived hosts', which has been published in final form at [Link to final article using the DOI]. This article may be used for non-commercial purposes in accordance with Wiley Terms and Conditions for Self-Archiving."

All outputs in CentAUR are protected by Intellectual Property Rights law, including copyright law. Copyright and IPR is retained by the creators or other copyright holders. Terms and conditions for use of this material are defined in the End User Agreement. 


\section{www.reading.ac.uk/centaur}

\section{CentAUR}

Central Archive at the University of Reading

Reading's research outputs online 
1 Exploring the symbiont diversity of ancient western redcedars: arbuscular

2 mycorrhizal fungi of long-lived hosts

3

4 Monika A. Gorzelak*, Brian J. Pickles† $\dagger$, Miranda M. Hart**

5

6 *Department of Forest and Conservation Science, University of British Columbia, Vancouver,

7 BC. V6T $1 Z 4$.

$8 \uparrow$ School of Biological Sciences, University of Reading, Harborne Building, Whiteknights,

9 Reading, RG6 8AS, UK.

$10 * *$ Department of Biology, University of British Columbia Okanagan, Kelowna, BC V1V 1V7,

11 Canada.

12

13 Keywords (4-6): ancient forest, beta-diversity, chronosequence, phylogenetic diversity,

14 microbial succession, western redcedar (Thuja plicata).

15

16 Corresponding author: Miranda Hart

$17 \quad$ Tel: +12508079398

18 Fax: +12508078830

19 Email: miranda.hart@ubc.ca

20

21 Running title: AMF communities of a long-lived host 


\section{Abstract (232 words)}

24 Arbuscular mycorrhizal fungi (AMF) are globally distributed, monophyletic root symbionts

25 with ancient origins. Their contribution to carbon cycling and nutrient dynamics is

26 ecologically important, given their obligate association with over $70 \%$ of vascular plant

27 species. Current understanding of AMF species richness and community structure is based

28 primarily on studies of grasses, herbs, and agricultural crops, typically in disturbed

29 environments. Few studies have considered AMF interactions with long-lived woody perennial

30 species in undisturbed ecosystems. Here we examined AMF communities associated with roots

31 and soils of young, mature, and old western redcedar (Thuja plicata) at two sites in the old-

32 growth temperate rainforests of British Columbia. Due to the unique biology of AMF,

33 community richness and structure were assessed using a conservative, clade-based approach.

34 We found 91 AMF OTUs across all samples, with significantly greater AMF richness in the

35 southern site, but no differences in richness along the host chronosequence at either site. All

36 host age classes harboured AMF communities that were overdispersed (more different to each

37 other than expected by chance), with young tree communities most resembling old tree

38 communities. A comparison with similar clade richness data obtained from the literature

39 indicates that western redcedar AMF communities are as rich as those of grasses, tropical trees,

40 and palms. Our examination of undisturbed temperate old growth rainforests suggests that

41 priority effects, rather than succession, are an important aspect of AMF community assembly

42 in this ecosystem. 


\section{Introduction}

44 Arbuscular mycorrhizal fungi (AMF) are an ancient lineage of obligate biotrophs (Redecker $e t$ 45 al. 2000; Bonfante \& Genre 2008), requiring symbiosis with roots to complete their lifecycle 46 (Smith \& Read 2008). The presence and composition of AMF impacts plant biodiversity (van

47 der Heijden et al. 1998), plant response to increases in $\mathrm{CO}_{2}$ (Terrer et al. 2016), nutrient cycling (Phillips et al. 2013; Johnson et al. 2015) and soil carbon sequestration (Averill et al. 2014). Given the global influence and distribution of AMF (Davison et al. 2015;

50 Soudzilovskaia et al. 2015), we know surprisingly little about how their communities are 51 structured in most ecosystems.

Current knowledge on the drivers of AMF community composition indicates that both dispersal limitation and habitat filtering play significant roles (Öpik et al. 2006, 2010; Kivlin et al. 2011). Recently it has been shown that host identity can exert a greater influence on AMF composition than competition between the fungi themselves (Davison et al. 2016). Temporal processes such as plant community succession may also structure AMF communities (Koske \& across a chronosequence (Dornelas et al. 2013). While community studies of AMF are important, the overwhelming research focus has been on easily manipulated, short-lived hosts

60 such as forbs and grasses (Ohsowski et al. 2014; Davison et al. 2015), thus our understanding 61 of AMF communities may overlook dynamics that occur over long time scales. Investigations of the impact of long-lived hosts on AMF community structure are few

63 (but see Hart et al. 2014). Undoubtedly, due to physiological differences, long-lived host trees 64 exert different influences on their AMF compared to hosts with shorter lifespans. Ontogenetic 65 studies suggest that early life stages (seedlings, saplings, and pole) provide less photosynthate 66 to symbionts than mature or old trees, particularly when they are establishing under a closed canopy in the shade (Thomas \& Winner 2002). This could cause AMF communities to shift in response to changing carbon supply (Bago et al. 2002, Ijdo et al. 2010). Further, given that 
some trees may live for millennia, AMF communities may differ in composition and turnover

70 ( $\beta$-diversity). For instance, it is known that plants in early successional systems have higher

71 AMF $\beta$-diversity, perhaps due to environmental heterogeneity (Christensen and Peet 1984).

72 Similarly, plants in late successional systems tend to exhibit lower AMF $\beta$-diversity, perhaps

73 due to environmental filtering (Derroire et al. 2016). While the idea of AMF and community

74 convergence has received some attention (Caruso et al. 2012, Maherali and Klironomos 2012),

75 whether this is true for AMF over successional time scales is not known.

Current ideas in community assembly theory suggest that ecological processes may not

77 be as easily inferred from patterns of species co-existence as previously expected (Gerhold et al. 2015). Overdispersion, in which species co-exist less often than expected by chance, is often assumed to represent the process of competitive exclusion: related species with comparable

80 traits will compete more intensely than more distantly related species. Clustering, in which

81 species co-exist more often than would be expected by chance, is often assumed to be caused

82 by niche partitioning, where competition is less important than the suitability of the

83 environment for that suite of organisms. Meta-analysis of competition experiments in plants

84 has shown little evidence to support a direct link between these patterns and processes (Cahill

85 et al. 2008), however, niche partitioning has been demonstrated in some detailed studies of 86 overdispersed communities (e.g. Cavender-Barnes and Pahlich 2009). Importantly, the case can

87 be made that overdispersion patterns can be created by both niche partitioning and competition

88 acting in tandem (Mayfield and Levine 2010), although clustering is less likely to be caused by

89 a myriad of interacting processes.

Here we explore the richness and diversity of AMF communities associated with

91 western redcedar (Thuja plicata Donn ex D. Don), a long-lived woody host; examining both

92 roots and soil.. We hypothesised that these long-lived plants would exert selective pressures on

93 their AMF symbionts that differ from those produced by herbs, grasses, and other short-lived 
94 hosts, due to differences in the availability of carbon resources, leading to: i) an increase in

95 AMF richness with increasing host age, and ii) succession of distinctive AMF communities

96 among host age classes.

$98 \quad$ Materials and methods

$99 \quad$ Field sites

100 Two study sites were selected within the Interior Cedar-Hemlock (ICH) Biogeographic Zone

101 (Ketcheson et al. 1991) of British Columbia, one at the northern range limit (53²45'45.68" N,

$\left.102121^{\circ} 13^{\prime} 5.93^{\prime \prime} \mathrm{W}\right)$ and the other in the southern end of the distribution $\left(49^{\circ} 40^{\prime} 44.47^{\prime \prime} \mathrm{N}\right.$,

$103117^{\circ} 43^{\prime} 5.92 " \mathrm{~W}$ ) within the ICHvk (very wet cool) and ICHdw (dry warm) variants,

104 respectively. Commonly known as the interior temperate rainforest, due to high annual

105 precipitation, these areas can represent continuous stands that have been present for thousands

106 of years, and are host to very large western redcedar trees; potentially 800-1000 years or older

107 in some cases, especially at the northern 'Ancient Forest' site $100 \mathrm{~km}$ east of Prince George.

108 The most abundant alternative AMF host species in the northern site were bunchberry (Cornus

109 canadensis) and devils club (Oplopanax horridus), whereas common snowberry

110 (Symphoricarpos albus), Oregon-grape (Mahonia sp.), twinflower (Linnea borealis), and false

111 box (Paxistima myrsinites) were the most abundant in the south.

$113 \quad$ Fungal community sampling

114 Trees were selected from three 'age classes' based on their diameter-at-breast-height (dbh):

115 young trees $(\mathrm{dbh}<5 \mathrm{~cm})$, mature trees $(\mathrm{dbh} 19-65 \mathrm{~cm})$, and old trees $(\mathrm{dbh} 150-455 \mathrm{~cm})$.

116 These age classes represent estimates of tree life stages, for which dbh is considered a useful

117 proxy, due to the tendency for western redcedar to rot from the centre outwards as it matures,

118 rendering the determination of tree age by coring impossible. Five trees were sampled per age

119 class at each site. From each tree, five fine root samples were obtained by digging along large 
120 roots, thus ensuring that sampled roots belonged to the sample tree. For three of the five trees

121 per age class, three soil cores $(2.5 \mathrm{~cm}$ diameter $)$ of the top $10 \mathrm{~cm}$ organic horizon were sampled

122 adjacent to each root sampled (within approx. $2 \mathrm{~m}$ of the base of the trunk). All samples were

123 sealed in plastic bags and kept on ice in a cooler for transport, prior to storage at $4{ }^{\circ} \mathrm{C}$.

124 Processing took place within 3 months of sample collection. Subsamples for both roots and

125 soil were pooled at the level of individual tree for subsequent analyses, for a total of 48

126 samples (15 root, 9 soil at each site).

Molecular methods

130 For each sample DNA was extracted from $150 \mathrm{mg}$ of randomly selected root segments (first

131 cleaned in deionized water), and from $250 \mathrm{mg}$ of homogenized soil, using the Powersoil®

132 DNA Isolation Kit (MO BIO Laboratories Inc., Carlsbad, CA, USA). Glomeromycota 28S

133 large sub-unit ribosomal DNA sequences were amplified using FLR3 (forward) and FLR4

134 (reverse) (Gollotte et al., 2004) primers, linked to 454-sequencing adapters and linkers. PCR

135 was carried out using 20pmol dNTPs, 3.5 $\mathrm{mM} \mathrm{MgCl}_{2}, 40 \mu \mathrm{g}$ BSA, 20 pmol of each primer, and

136 1U GoTaq with supplied buffer (Promega Corporation, WI, USA). Thermocycling conditions

137 were as follows: $95^{\circ} \mathrm{C}$ for 1 minute, 35 cycles of $95^{\circ} \mathrm{C}$ for 30 seconds, $58^{\circ} \mathrm{C}$ for 30 seconds,

$13872^{\circ} \mathrm{C}$ for 1 minute, followed by $72^{\circ} \mathrm{C}$ for 7 minutes and stored at $4^{\circ} \mathrm{C}$. PCR products were

139 cleaned and normalized to 1-2 ng/ $\mu \mathrm{L}$ using SequelPrep ${ }^{\mathrm{TM}}$ Normalization Plate (96) kit (Life

140 Technologies ${ }^{\mathrm{TM}}$, NY, USA). The samples were pooled and sequenced on a Genome Sequencer

141 FLX System, using Titanium Series reagents (Roche Applied Science) at the Vancouver

142 Prostate Centre. All sequences and sample information are available online

143 https://dx.doi.org/10.6084/m9.figshare.1451402.v1. 
146 Sequences were analysed using the default settings, unless otherwise noted, in QIIME 1.7.0

147 (Caporaso et al. 2010). OTUs were picked de novo using 97\% similarity using the UCLUST

148 algorithm (Edgar 2010). Chimera checking was performed using the usearch61 de novo

149 method. Sequence 'denoising' was not performed as it has been shown to alter beta-diversity in

150 AMF studies (Hart et al. 2015). Out of the 48 samples a single barcode was not recovered

151 (associated with an old tree soil sample from the northern site). Taxonomy was assigned using

152 the GenBank® database (http://www.ncbi.nlm.nih.gov) with the BLAST (nucleotide)

153 algorithm. All non-Glomeromycotan sequences $(<0.01 \%)$ were removed. A retained sequence

154 was considered to match known AMF taxa if its similarity to database sequences was $97 \%$ or

155 greater (Hart et al. 2015), however closest matches to existing 28S accessions within the

156 Glomeromycota at lower levels were retained and classed as 'unknown'.

Of the 201020 sequences generated, 70097 fulfilled the retention criteria and were

158 grouped into 1012 OTUs. The total number of these OTUs matching existing AMF sequences

159 at a similarity level of $97 \%+$ was 876 , of which 698 produced a $100 \%$ match, 111 at $99 \%, 40$ at

$16098 \%$, and 27 at a 97\% level. The remaining 136 OTUs did not match the database at the

161 typically acceptable level (matches varied from 89-96\%). Thus, approximately $13 \%$ of the

162 OTUs generated were potentially novel Glomeromycotan sequences. Of the 1012 OTUs 325

163 were singletons, leaving 687 clusters that contained 2 or more sequences. Rarefying to an even

164 sampling depth retained 581 sequences per root sample (total of 665 OTUs) or 91 sequences

165 per soil sample (total of 316 OTUs).

Due to concerns about diversity inflation resulting from the 454-pyrosequencing we

167 applied a monophyletic clade approach (MCA) to convert the raw OTU clusters into clades

168 within the Glomeromycota (see Lekberg et al. 2014). The MCA is an OTU delineation method

169 wherein sequence groups are manually combined based on membership within a monophyletic

170 clade. We followed the methodology of Lekberg et al. (2014), where the authors demonstrated

171 that the method is robust and generates community patterns that are comparable to OTU 
172 methods based on percentage similarity thresholds. The strength of the MCA method is that it

173 is grounded in evolutionary theory. This conversion of OTUs using MCA resulted in a total of

17491 Glomeromycotan clades. Two of these clades were 'sequence singletons' (contained a

175 single sequence), whereas five clades were 'sample singletons' (occurred in a single sample).

176 Each MCA was identified using the GenBank® database (http://www.ncbi.nlm.nih.gov) with

177 the BLAST (nucleotide) algorithm, which matched sequences within each clade to existing $28 \mathrm{~S}$

178 accessions. All of the subsequent community analyses presented below were performed using

179 the MCA data tables with sequence singletons removed. We also analysed the OTU data using

180 the same methods and additionally using variance stabilising transformations (McMurdie \&

181 Holmes, 2013). Ecological interpretations were not substantially different between the

182 approaches unless otherwise noted (for further details see Supporting Information).

184 AM fungal diversity of other host plants

185 To place western redcedar in the context of existing research into the fungal diversity of AM 186 hosts we compiled AMF community data from previous studies that examined trees, shrubs, 187 woody perennials, palms, grasses, and herbs. Due to the variability among marker genes for 188 AMF (see Thiéry et al., 2016), and the lack of data on AMF communities of long-lived hosts, 189 we limited our comparisons to studies that: i) presented data for multiple individuals of a 190 specific host species, ii) used 454 sequencing technology to obtain OTUs, and iii) expressed 191 AMF diversity at the clade-level by using MCA-type approaches (e.g. 'virtual taxa'; Öpik et al. 192 2010). This cladistic approach to AMF diversity was utilized to maximise the relevance of 193 comparisons between host species by removing the noise associated with OTU assignments, 194 particularly in regards to the differences in sensitivity levels between the LSU and SSU 195 regions. 
198 Sample-based rarefaction curves were calculated using 1000 permutations of random

199 subsampling without replacement for each site's root and soil MCA communities in EstimateS

200 version 9.1.0 (Colwell 2013). Clade richness differences were examined in a three-way

201 ANOVA in R (R-project Core Team, 2015) using the model: Richness $\sim$ Site * Age * Source.

202 Tukey's HSD test was applied post-hoc to determine which groups differed significantly.

AMF community differences were analysed using PERMANOVA by converting MCA

204 data into dissimilarity indices using Bray-Curtis (Sørensen) and $\beta_{\text {sim }}$ (Koleff et al. 2003) in R-

205 package 'vegan' (Oksanen et al. 2013), with the function 'anosim'. Multivariate dispersion

206 was assessed using the function 'betadisper'. Interpretation did not differ between indices, so

207 only the results of Bray-Curtis (Sørensen) index are presented.

AMF community ß-diversity partitioning was also applied to examine evidence of

209 structural changes between host age classes, analysing soil and root communities separately,

210 and using Mantel correlograms to test for autocorrelation in AMF community composition

211 within each site (see Borcard \& Legendre 2012). Three dissimilarity matrices were constructed

212 for each site using the B-diversity partitioning of Jaccard's index (Baselga 2010; Carvalho et al.

213 2013; Ensing \& Pither 2015) in R-package 'betapart' (Baselga et al. 2013) modified using the

214 additional R-code supplied in Ensing \& Pither (2015). Note that Jaccard's index is based on

215 binary presence/absence data and as such was conducted on the MCA dataset with sequence

216 singletons removed, considering each study site's root and soil samples separately. The

217 primary measure of dissimilarity was $\beta_{c c}$ (Jaccard's index of dissimilarity), which can be

218 subdivided into $\beta_{-3}$ (dissimilarity due to species replacement) and $\beta_{\text {rich }}$ (dissimilarity due to

219 richness differences). Dissimilarity matrices were standardized using the hellinger

220 transformation to achieve the requirement of second-order stationarity. For each analysis a

221 predictor distance matrix of age classes was obtained from $\log ($ host tree dbh). Mantel statistics

$222\left(r_{\mathrm{M}}\right)$ were calculated for age classes and tested for significance using 10,000 Monte-Carlo 
223 permutations and progressive Holm's correction for multiple testing. In each case, positive $r_{\mathrm{M}}$

224 values indicated positive autocorrelation (e.g. greater community similarity).

\section{Results}

227 Western redcedar AMF clade richness differences

228 Three-way ANOVA revealed that site was the only significant factor in producing clade 229 richness differences $\left(F_{1,35}=10.01 ; P=0.003\right)$, richness per sample did not differ significantly 230 between age classes $\left(F_{2,35}=0.09 ; P=0.913\right)$ or sample source $\left(F_{1,35}=1.57 ; P=0.219\right)$ and 231 there were no significant interaction terms. Significantly more AMF clades per sample were 232 found in the southern site (mean $31.5 \pm 2.66, \mathrm{n}=24$ ) than in the northern site (mean $20.2 \pm 1.18$, $233 \mathrm{n}=23$ ) (Tukey's HSD: South $>$ North; $P_{\text {adj }}=0.002$ ). Overall clade richness tended to be higher

234 in root than in soil samples, however, according to clade-based accumulation curves this

235 difference was only significant in the southern site (Fig. 1). Root sampling clearly approached 236 an asymptote (Fig. 1a), and sampling of both root and soil (Fig. 1b) communities was within 237 the $95 \%$ confidence interval of extrapolated clade richness obtained from a hypothetical 238 doubling of sample size. Similar results were obtained when examining the data based on 239 OTUs rather than clades (data not presented).

\section{AMF community composition}

242 Analysis of AMF community composition based on clades, and using a three-way

243 PERMANOVA of Bray-Curtis dissimilarities, revealed significant differences between sites

244 and between host age classes, but not between roots and soil (Table 1). The full model

245 accounted for $28 \%$ of the partial variance, and no difference in multivariate dispersion was

246 detected between groups (Table 1). A similar result was observed for the rarefied OTU

247 dataset, whereas analysis with variance stabilising transformations indicated significant

248 differences between root and soil communities (Supporting Information Table S1). 
Differences in community composition between sites, age classes, and sample source,

250 are illustrated in Fig. 2. Acaulospora spp. were only present in significant numbers in northern

251 samples (Fig. 2a-f). Acaulospora and Rhizophagus spp. were most abundant in northern roots

252 of old trees (Fig. 2c).. These roots also contained fewer sequences from unknown clades (Fig.

253 2c), compared to young trees (Fig. 2a). A greater proportion of sequences from Glomus clades

254 were found in southern site samples in general (Fig. 2g-1) and in young northern site samples

255 (Fig. 2a,d). Overall, more novel taxa were found in the northern site.

256 Evidence of community structure related to host age was detected in root (Fig. 3) and

257 soil (Fig. 4) communities, with both study sites exhibiting similar $\beta$-diversity patterns. The

258 AMF communities of trees within each age class were overdispersed (e.g. significantly less

259 similar to each other in clade composition; Fig. 3a,b and Fig. 4a,b). Comparison between age

260 classes revealed that AMF communities of younger trees (smallest dbh class) tended to be

261 autocorrelated (e.g. were significantly more similar in clade composition) with those of the

262 oldest trees (largest dbh class) (Fig. 3a and Fig. 4a,b). Partitioning of Jaccard's dissimilarity

263 index $\left(\beta_{\mathrm{cc}}\right)$ into its turnover $\left(\beta_{-3}\right)$ and richness $\left(\beta_{\text {rich }}\right)$ components, indicated that the AMF

264 community patterns were mostly driven by community turnover, which was overdispersed

265 within age classes (Fig. 3c,d and Fig. 4c). However, soil communities displayed

266 autocorrelation between the AMF communities of young and old trees (Fig. 4c,d). Richness

267 differences between AMF communities of the youngest and oldest trees were autocorrelated,

268 but only significantly so in the northern site (Fig. 3e and Fig. 4e). In all cases, a significant

269 increasing linear trend in $r_{M}$ values from negative in trees of a similar age to positive between

270 the youngest and oldest trees was observed with increasing host pair age difference $\left(r^{2}=0.69\right.$

271 to $0.83, P<0.01)$.

273 Comparison with other AM hosts 
274 In terms of overall AMF clade richness derived from host root sampling, western redcedar was

275 ranked second across all host growth forms (Fig. 5; Supporting Information Table S2), with

276 only the palm Podococcus barteri observed to associate with a greater number of clades.

277 When examined from the perspective of AMF clade richness per individual host plant, western

278 redcedar communities were again ranked first, but tied for first place with two long-lived

279 tropical tree species (Polyalthia suaveolens and Santiria trimera), two palms (Bactris

280 rhaphidacantha and Podococcus barteri), and two grasses (Agropyron cristatum and Potentilla

281 acaulis) (Fig. 5; Supporting Information Table S2). Using clade-based approaches to AMF

282 richness, the number of clades encountered on western redcedar was consistently greater than

283 those found on perennial woody and herbaceous plants, and the majority of other tree species

284 for which comparable data exists (much of which is drawn from the work of Davison et al.

285 2015).

286

287 Discussion

288 Western redcedar is a long-lived tree that exhibits high clade richness in its associated AMF

289 communities. Despite significant differences in the community compostion between sites, the

290 autocorrelation patterns were similar at both sites, implying that the cedar host may create the

291 same patterns in distinct locations. In particular, we observed overdispersion in AMF $\beta$ -

292 diversity within each host age class at both study locations - shifts from overdispersion to

293 neutral structure to autocorrelation took place between pairs of hosts as the difference in host

294 age increased. This study represents one of the first investigations of the symbiotic AMF

295 community of a long-lived gymnosperm host using next-generation sequencing techniques, and

296 presents an important starting point for further examination of these under-explored systems.

298 Clade richness differences 
299 We had anticipated that older trees would exhibit higher clade richness, accumulating more

300 AMF over their lifetime. However, this was not supported by the data. There is some evidence

301 for higher AMF species richness in mature breadfruit (Hart et al. 2014), but in general there is

302 little support for richness increasing with host age, simply because there is a dearth of studies

303 on long-lived AM host trees. This topic requires much more research.

The greatest differences in clade richness were between the northern and southern study

305 locations, with the southern site containing a significantly greater number of clades. This is a

306 typical pattern for biodiversity in general (Hillebrand 2004), and fungal biodiversity in

307 particular (Tedersoo et al. 2014), although we note that ectomycorrhizal fungi are highly

308 diverse in boreal and arctic ecosystems (Timling et al. 2012; Taylor et al. 2014). In our study,

309 samples from the Northern site had a greater number of clades matching Acaulospora and

310 Rhizophagus spp. However, at least two-thirds of the clades in each sample failed to match

311 existing database sequences at the species or genus level. Although this likely reflects the lack

312 of LSU sequences deposited in the NCBI database for AMF it also opens up the possibility that

313 a large number of currently unknown AMF reside in these communities. We propose that

314 further investigation of western redcedar mycorrhizas may be most profitably targeted at the

315 communities associated with both mature trees and the oldest extant trees. The use of a variety

316 of molecular markers (see Hart et al. 2015) will be key to determining how many of their

317 symbionts truly represent previously undiscovered AMF clades.

319 Clade richness differences between AM hosts

320 Our compilation of data from the literature on the number of clades per host species and

321 individual host plant, revealed a wide range in the values of these richness measures.

322 Considering the data in terms of rank order alone western redcedar was at the upper end of the

323 richness distribution: $2^{\text {nd }}$ for total number of AMF clades and joint $1^{\text {st }}$ for number of clades per

324 individual sample. We encourage future research using multiple estimators of AMF diversity 
(Hart et al. 2015) that focuses on old individuals selected from long-lived host tree species, and

326 particularly gymnosperms. While many mycorrhizal studies of gymnosperms exist, they focus

327 almost exclusively on ectomycorrhizal hosts (Chaudhary et al. 2016).

329 AMF clade community composition

330 Overdispersion of AMF communities within each host age class was not expected. That the

331 same pattern of beta-diversity was observed at both of our study sites suggests a general pattern

332 within inland temperate rainforests, but further studies are required and comparison to coastal

333 western redcedar forests would be informative. Conversely, in northern site roots and in the

334 soils at both sites, the youngest trees hosted AMF communities that were significantly more

335 similar to those of the oldest trees than was expected (autocorrelated). Overdispersion has

336 historically been interpreted as evidence of competitive exclusion structuring a community (see

337 reviews by HilleRisLambers et al., 2012; Gerhold et al. 2015). That is, closely related species

338 exclude each other because their trait similarity leads to more intense competition. Whereas the

339 opposite pattern, increased clustering (co-occurring more often than expected by chance)

340 indicates environmental filtering. In the latter case, competition is less important in structuring

341 a community than environmental conditions. This pattern does not manifest consistently

342 (Cahill et al., 2008), and it has been argued that only clustering is indicative of environmental

343 filtering, whereas the pattern of overdispersion can be caused by many interacting forces,

344 including but not limited to competitive exclusion (Mayfield and Levine 2010;

345 HilleRisLambers et al., 2012; Alexandrou et al., 2015; Gerhold et al. 2015; Li et al., 2015). In

346 our study, overdispersion indicates that, within a cohort, each tree assembled a unique

347 community of AMF. However, autocorrelation increased as the age (dbh) difference between

348 trees increased, resulting in young trees having similar AMF communities to those of the oldest

349 trees. Our interpretation is that this represents a 'parent tree' or 'nurse tree' effect in which

350 young trees inherit their AMF communities from the old trees that surround them when they 
establish. In a temperate rainforest formed by long-lived tree species, in which sudden

352 stochastic events (e.g. fires) are not part of the typical cycle of regeneration, seedlings are

353 likely to collect their first symbionts via hyphal connections from the roots of surrounding

354 trees. If so, the maintenance of overdispersion within a cohort suggests a major role for priority

355 effects in determining the composition of AMF on any given host tree. Although priority

356 effects have not previously been investigated in long-lived hosts, strong AMF priority effects

357 have been observed in lab studies on the roots of an annual legume (Medicago truncatula;

358 Werner and Kiers, 2015).

Redcedar ontogeny and AMF community structure

The prevailing theory that old trees become less productive with age (Weiner $\&$

362 Thomas 2001) has recently been challenged by studies on California redwood (Sequoia

363 sempervirens) (Sillett et al. 2010; Stephenson et al. 2014). While detailed work deciphering the

364 ontogeny of western redcedar remains to be performed, much is known about related species

365 (Koch et al. 2004) and conifers in general (Meinzner et al. 2011). Careful measurements mid-

366 stem and at the crowns indicate that size is the greatest predictor of tree productivity, and

367 indeed, old trees become more productive with age (Sillett et al. 2015). If western redcedar

368 similarly become more productive with age, the old redcedars sampled in our study are likely

369 to have been the most photosynthetically active. Hence young trees would be expected to

370 exude the lowest quantities of sugar, mature trees variable levels dependent on their dominance

371 in the canopy, and old trees would exude the most sugar. Yet, despite having the necessary

372 resources to deliver larger quantities of sugar to symbionts, old western redcedars do not

373 appear to influence their communities toward a specific composition.

Our data suggests that priority effects within the AMF fungi dominate, and two

375 scenarios for this process generating this seem likely: i) the host has no control over AMF

376 assembly, and initial AMF colonists exclude subsequent fungi, or ii) the host rewards 
mutualistic behaviour with more resources (Bever et al. 2009, Kiers et al. 2011), which

378 increases their ability to exclude other AMF. In both of these cases priority effects are acting

379 at the AMF community level, but in one case the tree has no control (the 'mycocentric' view

380 (Staddon 2005)), and in the other the tree influences the fungus (the 'phytocentric' view

381 (Johnson \& Gehring 2007)). In general the extent to which one partner or the other is in control

382 remains unclear, particularly in natural, diverse AMF communities, although recent evidence

383 suggests that it is beneficial for a tree to maintain a diversity of fungal symbionts throughout its

384 life time (Arguello et al. 2016).

385 In conclusion, we did not find evidence of succession from young to mature to old tree

386 AMF communities nor did we find that old trees harbour unique AMF communities, although

387 we did find evidence of previously undescribed fungi associated with western redcedar roots.

388 AMF communities associated with young trees most closely resembled those with old tree,

389 suggesting that trees may be acquiring their symbionts from adjacent roots.. Mature tree AMF

390 communities did not resemble those associated with old or young trees. These trees may

391 represent a cohort that acquired their symbionts from the previous generation of old trees that

392 have long since died. If so, they are the future source of inoculants for young trees, if they

393 survive to old age.

394 Our study is the first to consider host age as a structuring force of AMF communities.

395 While we did not find the patterns we expected, our study revealed that community structure

396 may be transferred from old trees to young trees, which is important for understanding the

397 AMF communities of western redcedar. Whether similar patterns are important in other long-

398 lived AMF hosts remains to be tested. 
403

404

406

407

408

409

410

411

412

413

414

415

416

417

418

419

420

421

422

423

424

425

426

427

428

\section{Acknowledgements}

We thank Alicia Tymstra for lab assistance, Phil Burton for arranging transportation to the Ancient Forest near Prince George, Tamara Kostya for assistance in sample collection, and Dave Ensing for providing the R-code for $ß$-diversity partitioning. We also thank the editor and anonymous reviewers for their invaluable comments. This work was funded by NSERC Discovery Grant (MMH).

9

(1)




\section{References}

430 Alexandrou MA, Cardinale BJ, Hall JD, Delwiche F, Fritschie K, Narwani A, Venail PA, Bentlage B, Pankey MS, Oakley TH, et al. (2014) Evolutionary relatedness does not

Arguello A, O’Brien MJ, van der Heijden MG et al. (2016) Options of partners improve carbon predict competition and co-occurrence in natural or experimental communities of green

Averill C, Turner BL, Finzi AC (2014) Mycorrhiza-mediated competition between plants and decomposers drives soil carbon storage. Nature, 505, 543-5.

Bago B, Pfeffer PE, Zipfel W, Lammers P, Shachar-Hill Y (2002) Tracking metabolism and imaging transport in arbuscular mycorrhizal fungi. Plant and Soil, 244, 189-197.

Baselga A (2010) Partitioning the turnover and nestedness components of beta diversity. Global Ecology and Biogeography, 19, 134-143.

Baselga A, Orme D, Leprieur F (2013) betapart: Partitioning beta diversity into turnover and nestedness components. $R$ package ver 1.3 .

Bonfante P, Genre A (2008) Plants and arbuscular mycorrhizal fungi, an evolutionarydevelopmental perspective. Trends in Plant Science, 13, 492-498.

Bever JD, Richardson SC, Lawrence BM, Holmes J, Watson M (2009) Preferential allocation to beneficial symbiont with spatial structure maintains mycorrhizal mutualism. Ecology Letters, 12, 13-21.

Borcard D, Legendre P (2012) Is the Mantel correlogram powerful enough to be useful in ecological analysis? A simulation study. Ecology, 93, 1473-1481.

Cahill JF, Kembel SW, Lamb EG, Keddy PA (2008) Does phylogenetic relatedness influence the strength of competition among vascular plants? Perspectives in Plant Ecology, Evolution and Systematics, 10, 41-50. 
Caporaso JG, Kuczynski J, Stombaugh J et al. (2010) QIIME allows analysis of highthroughput community sequencing data. Nature Methods, 7, 335-336.

Caruso T, Hempel S, Powell JR, Barto EK, Rillig MC (2012) Compositional divergence and convergence in arbuscular mycorrhizal fungal communities. Ecology, 92, 1115-1124.

Carvalho JC, Cardoso P, Borges PAV, Schmera D, Podani J (2013) Measuring fractions of beta

Colwell R (2013) EstimateS: Statistical estimation of species richness and shared species from

Davison J, Moora M, Öpik M et al. (2015) Global assessment of arbuscular mycorrhizal fungus

Dornelas M, Magurran AE, Buckland ST et al. (2013) Quantifying temporal change in samples. URL http://purl.oclc.org/estimates.

Davison J, Moora M, Jairus T et al. (2016) Hierarchical assembly rules in arbuscular mycorrhizal (AM) fungal communities. Soil Biology and Biochemistry, 97, 63-70. diversity reveals very lowendemism. Science, 127, 970-973.

Derroire G, Balvanera P, Castellanos-Castro C, Decocq G, Kennard DK, Lebrija-Trejos E, Leiva JA, Odon PC, Powers JS, Rico-Gray V, et al. (2016) Resilience of tropical dry forests a meta-analysis of changes in species diversity and composition during secondary succession. Oikos, 125, 1386-1397. biodiversity: challenges and opportunities. Proceedings of The Royal Society B: Biological 
Sciences, 280, 20121931.

482 Edgar RC (2010) Search and clustering orders of magnitude faster than BLAST. Bioinformatics, 26, 2460-2461.

484 Ensing DJ, Pither J (2015) A novel multiple-site extension to pairwise partitioned taxonomic beta diversity. Ecological Complexity, 21, 62-69.

Gerhold P, Cahill JF, Winter M, Bartish IV, Prinzing A (2015) Phylogenetic patterns are not proxies of community assembly mechanisms (they are far better). Functional Ecology, 29, $600-614$.

Gollotte A, Van Tuinen D, Atkinson D (2004) Diversity of arbuscular mycorrhizal fungi colonising roots of the grass species Agrostis capillaris and Lolium perenne in a field experiment. Mycorrhiza, 14, 111-117.

Hart MM, Aleklett K, Chagnon P et al. (2015) Navigating the labyrinth: a guide to sequencebased, community ecology of arbuscular mycorrhizal fungi. New Phytologist, 207, 235247.

Hart MM, Gorzelak M, Ragone D, Murch SJ (2014) Arbuscular mycorrhizal fungal succession in a long-lived perennial. Botany, 320, 313-320.

Hillebrand HH (2004) On the generality of the latitudinal diversity gradient. The American Naturalist, 163, 192-211.

Hillerislambers J, Adler PB, Harpole WS, Levine JM, Mayfield MM. (2012) Rethinking community assembly through the lens of coexistence theory. Annual Review of Ecology

van der Heijden MG, Klironomos JN, Ursic M et al. (1998) Mycorrhizal fungal diversity determines plant biodiversity, ecosystem variability and productivity. Nature, 396, 69-72. with contrasting life-history strategies differ in their responses to repeated defoliation? FEMS Microbiology Ecology, 72, 114-122. 
Johnson NC, Gehring CA (2007) Mycorrhizas: symbiotic mediators of rhizosphere and ecosystem processes. Ecological Applications, 7, 171-182.

Johnson NC, Wilson GWT, Wilson JA, Miller RM, Bowker MA (2015) Mycorrhizal phenotypes and the Law of the Minimum. New Phytologist, 205, 1473-1484.

Ketcheson M, Braumandl T, Meidinger D et al. (1991) Chapter 11: Interior Cedar - Hemlock Zone. In: Ecosystems of British Columbia. Special Report Series No. 6. (eds Meidinger D, Pojar J), pp. 167-181. British Columbia Ministry of Forests Research Branch, Victoria, BC.

Kiers ET, Duhamel M, Beesetty Y et al. (2011) Reciprocal rewards stabilize cooperation in the mycorrhizal symbiosis. Science, $\mathbf{3 3 3}, 880-882$.

Kivlin SN, Hawkes C V, Treseder KK (2011) Global diversity and distribution of arbuscular mycorrhizal fungi. Soil Biology and Biochemistry, 43, 2294-2303.

Koch GW, Sillett SC, Jennings GM, Davis SD (2004) The limits to tree height. Nature, 428, $851-854$.

Koleff P, Gaston KJ, Lennon JJ (2003) Measuring beta diversity for presence-absence data. Journal of Animal Ecology, 72, 367-382.

Koske ARE, Gemma JN (1997) Mycorrhizae and succession in plantings of beachgrass in sand dunes. American Journal of Botany, 84, 118-130.

Lekberg Y, Gibbons SM, Rosendahl S (2014) Will different OTU delineation methods change

Li S, Cadotte MW, Meiners SJ, Hua Z shuang, Jiang L, Shu W (2015) Species colonisation, not competitive exclusion, drives community overdispersion over long-term succession.

531 Maherali H, Klironomos JN. 2012. Phylogenetic and trait-based assembly of arbuscular mycorrhizal fungal communities. PLoS ONE 7, e36695. 
Mayfield MM, Levine JM (2010) Opposing effects of competitive exclusion on the phylogenetic structure of communities. Ecology Letters, 13, 1085-1093.

McMurdie PJ, Holmes S(2013) phyloseq: An R package for reproducible interactive analysis and graphics of microbiome census data.PLoS ONE. 8(4):e61217

Meinzner FC, Lachenbruch B, Dawson TE (Eds.) (2011) Size and age related changes in tree structure and function. Springer, New York and London.

Ohsowski BM, Zaitsoff PD, Opik M, Hart MM (2014) Where the wild things are: looking for uncultured Glomeromycota. New Phytologist, 204, 171-179.

Oksanen AJ, Blanchet FG, Kindt R et al. (2013) vegan: Community Ecology Package.

Öpik M, Moora M, Liira J, Zobel M (2006) Composition of root-colonizing arbuscular mycorrhizal fungal communities in different ecosystems around the globe. Journal of Ecology, 94, 778-790.

Öpik M, Vanatoa A, Vanatoa E et al. (2010) The online database MaarjAM reveals global and ecosystemic distribution patterns in arbuscular mycorrhizal fungi (Glomeromycota). New Phytologist, 188, 223-41.

Phillips RP, Brzostek E, Midgley MG (2013) The mycorrhizal-associated nutrient economy : a new framework for predicting carbon - nutrient couplings in temperate forests. New Phytologist, 199, 41-51.

Redecker D, Kodner R, Graham LE (2000) Glomalean fungi in the Ordovician. Science, 289, 1920-1921.

Sillett SC, Van Pelt R, Carroll AL et al. (2015) How do tree structure and old age affect growth potential of california redwoods? Ecological Monographs, 85, 181-212.

Sillett SC, Van Pelt R, Koch GW et al. (2010) Increasing wood production through old age in tall trees. Forest Ecology and Management, 259, 976-994.

Smith S, Read D (2008) Mycorrhizal Symbiosis. Academic Press, London.

Soudzilovskaia NA, Douma JC, Akhmetzhanova AA et al. (2015) Global patterns of plant root 
colonization intensity by mycorrhizal fungi explained by climate and soil chemistry. Global Ecology and Biogeography, 24, 371-382.

Souza FA, Dalpé Y, Declerck S, Providencia IE, Séjalon-Delmas N.(2005) Life history strategies in Gigasporaceae: insight from monoxenic culture. Soil Biology Vol. Ed. S. Declerck, D.-G. Strullu, and A. Fortin. Springer-Verlag Berlin-Heidelberg 2005. p 73-91

Staddon PL (2005) Mycorrhizal fungi and environmental change : the need for a mycocentric approach. New Phytologist, 167, 635-637.

Stephenson NL, Das AJ, Condit R et al. (2014) Rate of tree carbon accumulation increases

Timling I, Dahlberg A, Walker D (2012) Distribution and drivers of ectomycorrhizal fungal communities across the North American Arctic. Ecosphere 3, 1-25.

584 Weiner J, Thomas SC (2001) The nature of tree growth and the age - related decline in forest 

productivity. Oikos, 2, 1996-1998.

586 Werner G, Kiers ET (2014) Order of arrival structures arbuscular mycorrhizal colonization of $587 \quad$ plants. New Phytologist, 10.1111/nph.13092

588

589

590 
Data Accessibility

592 DNA sequences: Sequences and supporting information are available at

593 http://dx.doi.org/10.6084/m9.figshare.1451402

\section{Author contributions}

596 M.A.G. and M.M.H designed the study, collected the data, and contributed to the writing and

597 editing. M.A.G. performed the lab work and bioinformatics, and produced the OTU and MCA

598 tables. B.J.P. analysed the data in R and EstimateS, drafted the manuscript, compiled the data

599 on AMF communities of other AM hosts and contributed to the writing and editing.

600

601 Supporting Information

602 Additional supporting information may be found in the online version of this article.

603 Table S1. Analysis of OTU community sequence abundance data using PERMANOVA (9999

604 permutations, stratified by source) and either: variance stabilising transformations vst and rlog

605 (Euclidean distances) following independent filtering, raw abundance (Bray-Curtis

606 dissimilarity), or rarefied abundance (Bray-Curtis dissimilarity).

607 Table S2. Comparison of the observed number of AMF taxa found on the roots of different

608 host species using 454 pyrosequencing and classification using the virtual taxa (VT) or

609 monophyletic clade approach (MCA). 
611 Figure 1. Taxonomic accumulation curves and extrapolated community richness based on

612 MCA data for a. roots and b. soils. White circles and black lines represent Northern samples.

613 Grey circles and grey lines represent Southern samples. Solid lines with and without circles

614 indicate estimated mean richness and extrapolated mean richness, respectively. Dashed lines

615 indicate $95 \%$ confidence intervals.

616 Figure 2. Proportional composition of AMF root and soil communities based on mean

617 sequence abundance per host at the clade level associated with western redcedar of increasing

618 age at each study site. Panels represent proportional sequence abundance at: Northern site, (a)

619 young root $(\mathbf{b})$ mature root $(\mathbf{c})$ old root $(\mathbf{d})$ young soil (e) mature soil (f) old soil; and Southern

620 site, $(\mathbf{g})$ young root $(\mathbf{h})$ mature root $(\mathbf{i})$ old root $(\mathbf{j})$ young soil $(\mathbf{k})$ mature soil (l) old soil.

621 Legend indicates phylogenetic level to which AMF clade could be identified.

622 Figure 3. Mantel correlogram analysis of AMF root MCA community ß-diversity partitions

623 using host tree dbh as a proxy for host age. (a) Northern site root $\beta_{\text {cc }}$ (c) Northern site root $\beta_{-3}$

624 (e) Northern site root $\beta_{\text {rich }}(\mathbf{b})$ Southern site root $\beta_{\text {cc }}$ (d) Southern site root $\beta_{-3}(\mathbf{f})$ Southern site

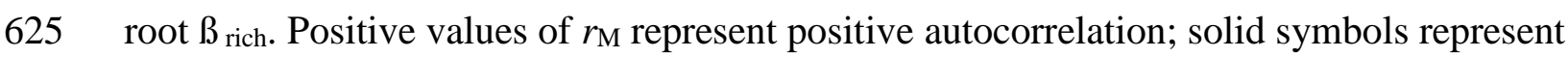
626 significant values following 10000 Monte Carlo randomizations and sequential Holm's 627 correction for multiple testing.

628 Figure 4. Mantel correlogram analysis of AMF soil MCA community ß-diversity partitions 629 using host tree dbh as a proxy for host age. (a) Northern site root $\beta_{\text {cc }}$ (c) Northern site root $\beta_{-3}$

630 (e) Northern site root $\beta_{\text {rich }}(\mathbf{b})$ Southern site root $\beta_{\text {cc }}$ (d) Southern site root $\beta_{-3}$ (f) Southern site 631 root $\beta_{\text {rich. }}$ Positive values of $r_{\mathrm{M}}$ represent positive autocorrelation; solid symbols represent 632 significant values following 10000 Monte Carlo randomizations and sequential Holm's 633 correction for multiple testing.

634 Figure 5. Comparison of AMF clade richness detected on the roots of different host species 635 using 454 pyrosequencing. Circles represent individual host species, bars represent s.e.m., and 
636 circles with solid borders are jointly ranked first for number of clades per individual. Data for

637 individual host species, and the study this data was obtained from, are presented in Supporting 638 Information. 
639 Table 1. Analysis of rarefied MCA community data with the Bray-Curtis dissimilarity index

640 using PERMANOVA (9999 permutations, stratified by source) and testing for homogeneity of 641 multivariate dispersions.

\begin{tabular}{lllll}
\hline Factor & DF & $\boldsymbol{F}$ & partial $\boldsymbol{r}^{\mathbf{2}}$ & $\boldsymbol{P}$ \\
\hline Site (Si) & 1 & $\mathbf{2 . 1 7}$ & 0.05 & $\mathbf{0 . 0 2 2}$ \\
Age (A) & 2 & $\mathbf{1 . 6 8}$ & 0.07 & $\mathbf{0 . 0 3 5}$ \\
Source (So) & 1 & 0.74 & 0.02 & 0.403 \\
Si x A & 2 & 1.39 & 0.06 & 0.114 \\
Si x So & 1 & 0.73 & 0.02 & 0.691 \\
A x So & 2 & 0.73 & 0.03 & 0.788 \\
Si x A x So & 2 & 0.61 & 0.03 & 0.906 \\
Residuals & 35 & & 0.72 & \\
\end{tabular}

Multivariate dispersion

\begin{tabular}{llll}
\hline Factors & 11 & 0.95 & 0.511
\end{tabular}

Residuals $\quad 35$

642 Values in bold are significant at the $\alpha \leq 0.05$ level.

643 Site $=$ north, south $;$ Age $=$ young, mature, old , Source $=$ root, soil 
a.

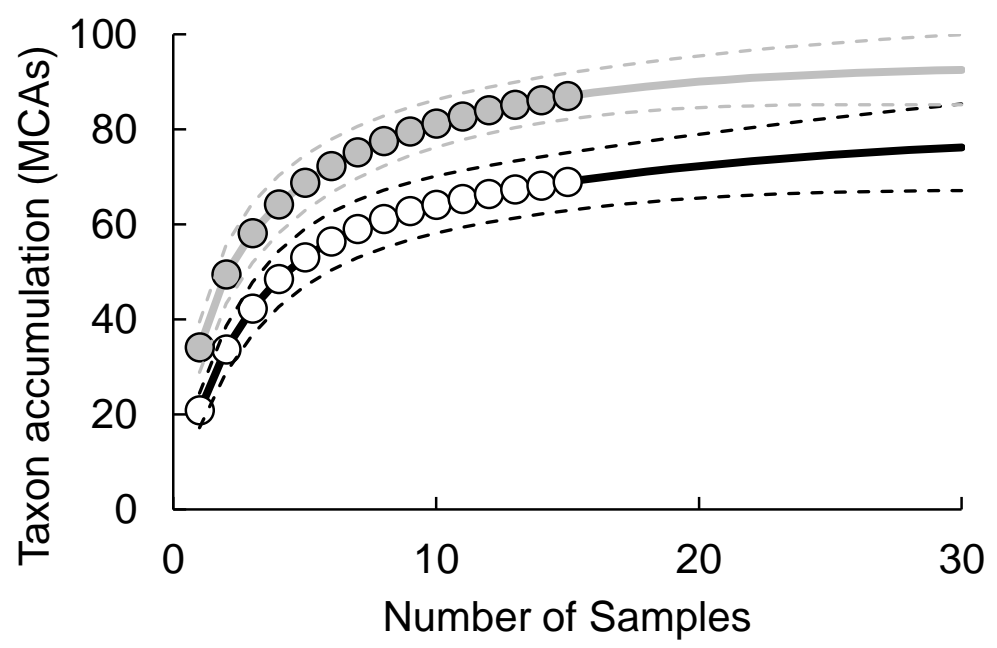

b.

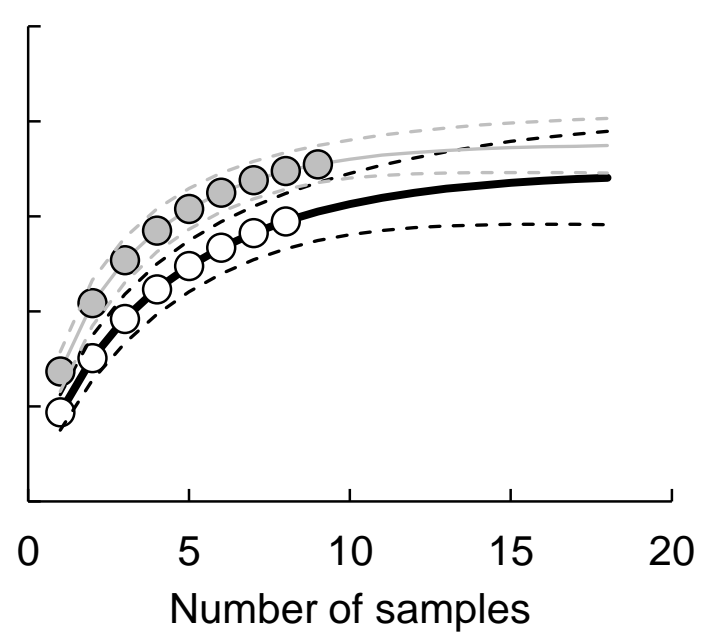



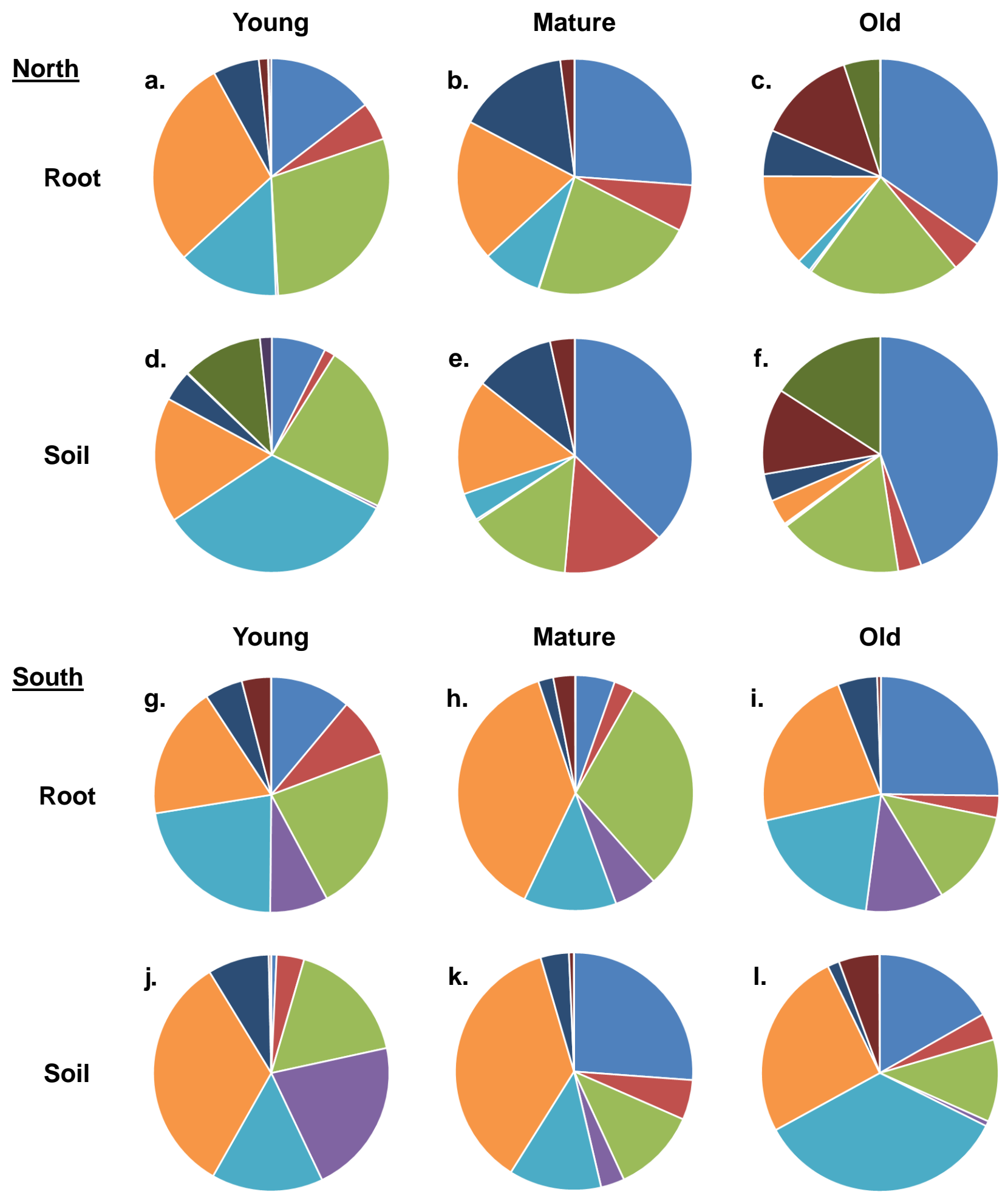

\begin{tabular}{|c|c|}
\hline Unknown (Glomeromycota) & - Unknown (Glomeromycetes) \\
\hline - Unknown (Glomerales) & - Unknown (Glomeraceae) \\
\hline - Unknown (Glomus) & Glomus spp. \\
\hline - Claroideoglomus spp. & - Rhizophagus spp. \\
\hline Acaulospora spp. & Diversispora sp. \\
\hline
\end{tabular}


AM fungi root communities

a.

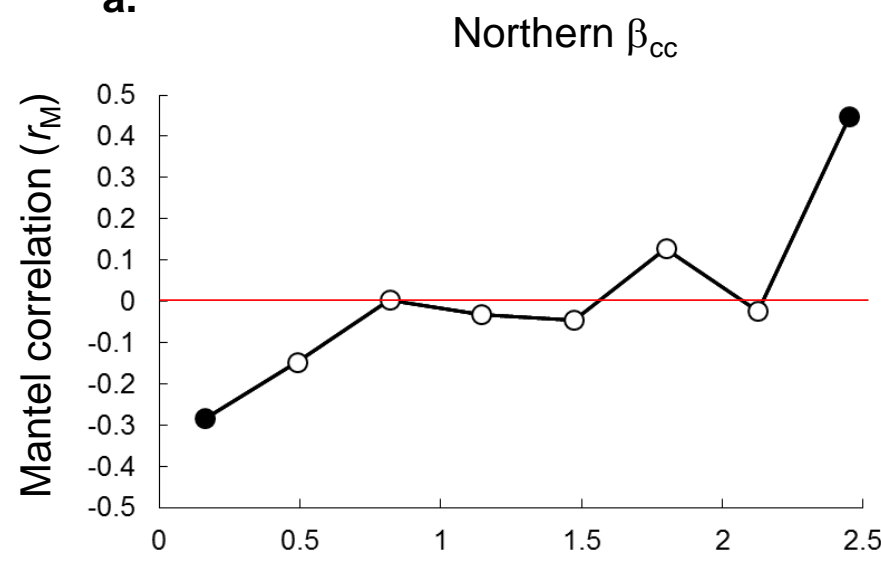

c.

Northern $\beta_{-3}$

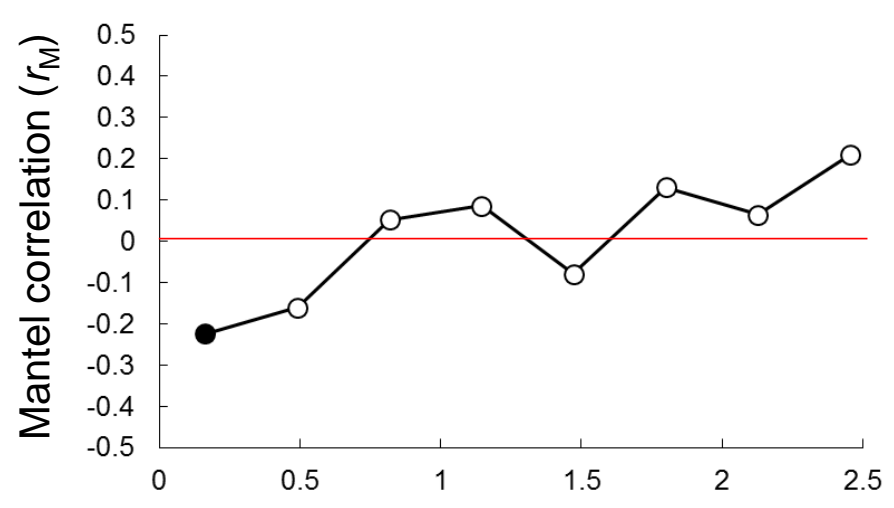

e.

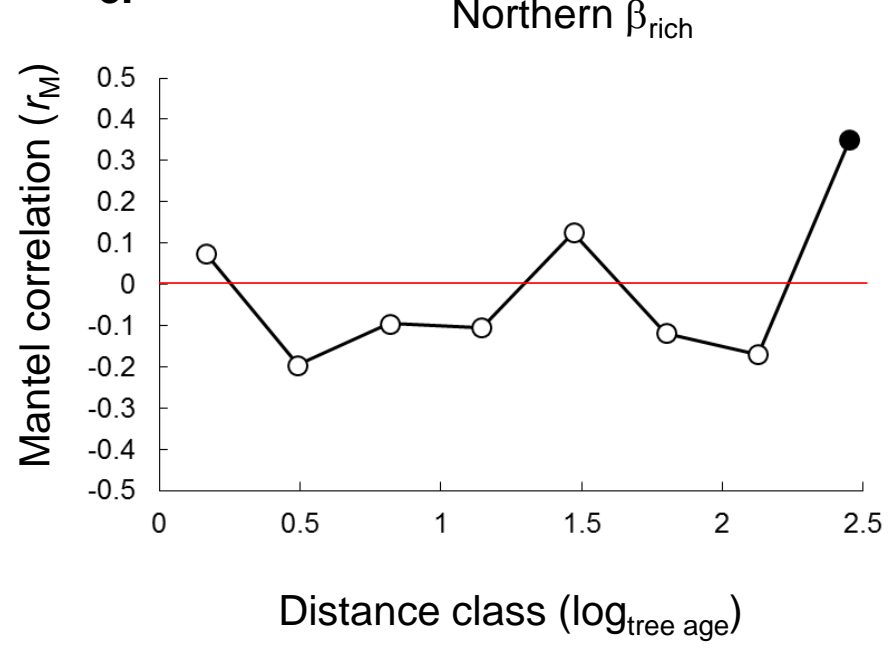

b.

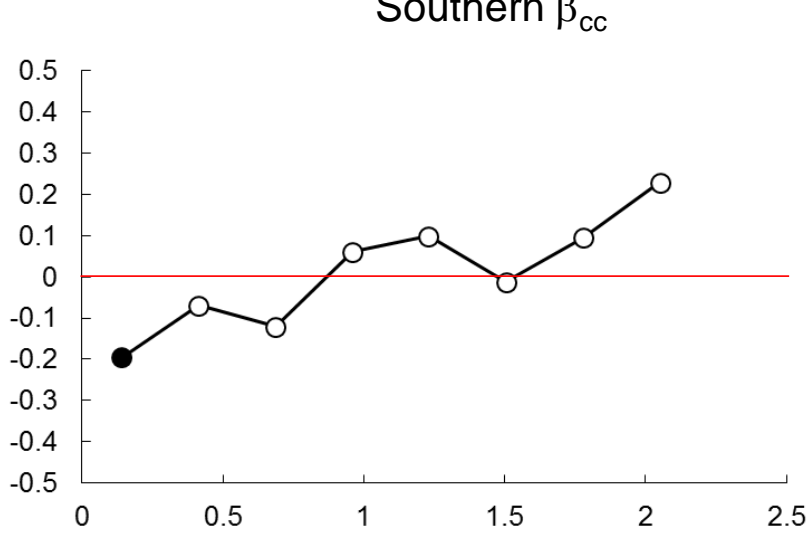

d.

Southern $\beta_{-3}$

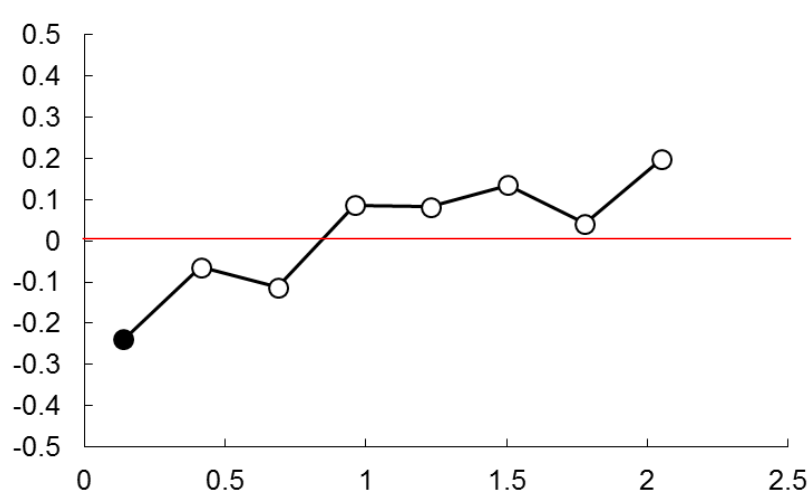

f.

Southern $\beta_{\text {rich }}$

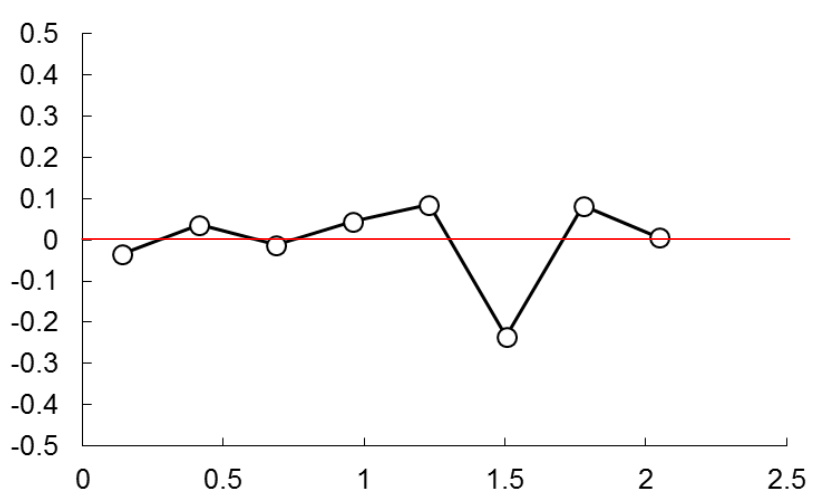

Distance class $\left(\log _{\text {tree age }}\right)$ 
AM fungi soil communities

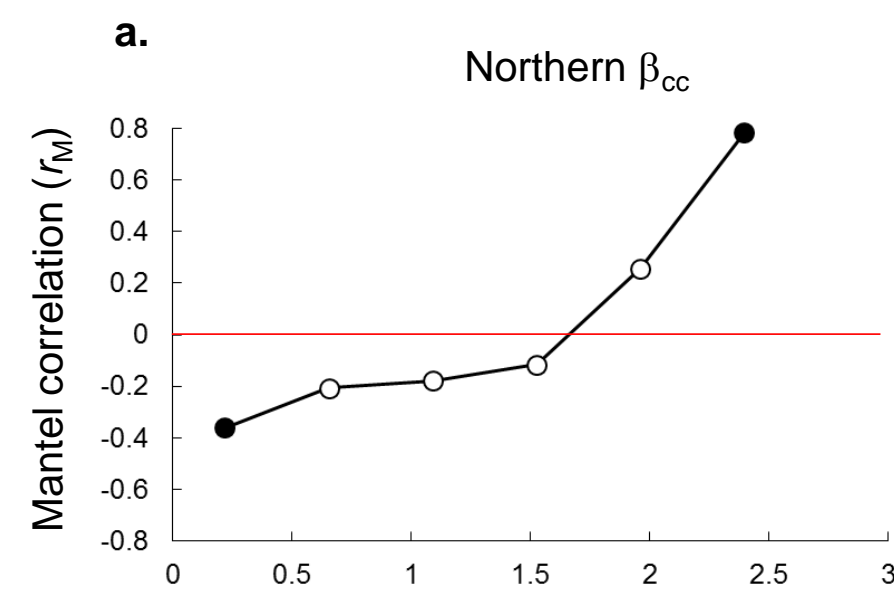

b.

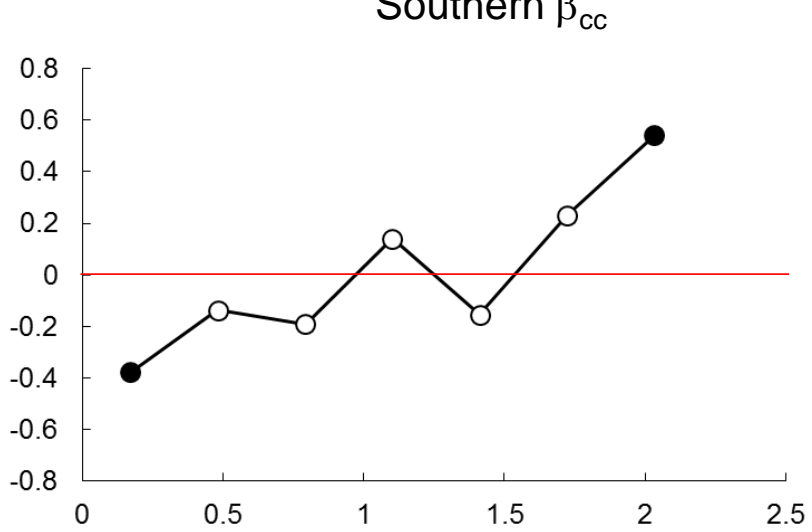

C.

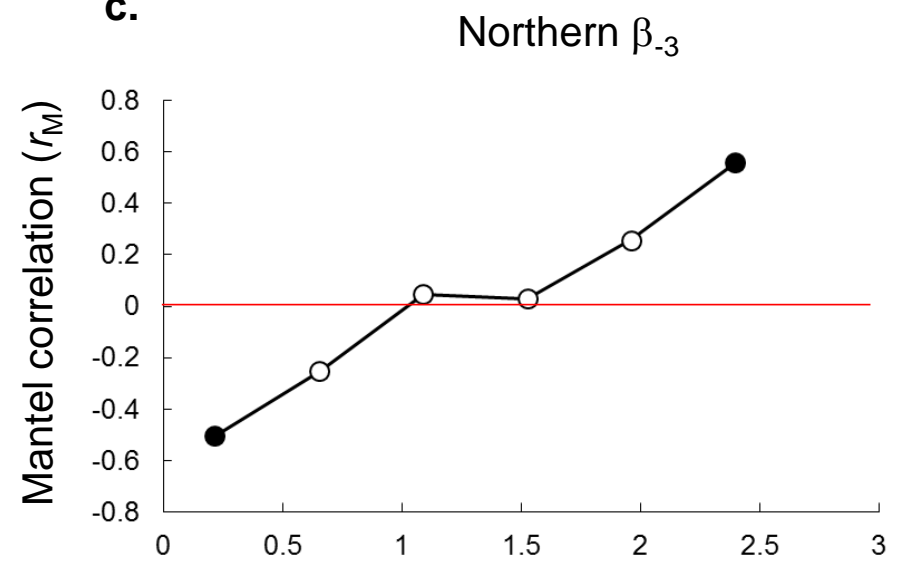

d.



f. Southern $\beta_{\text {rich }}$

Northern $\beta_{\text {rich }}$

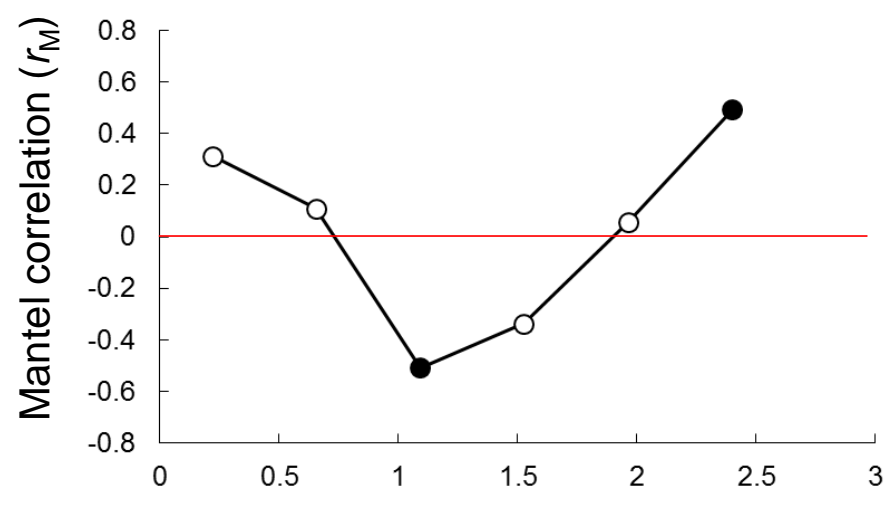

Distance class ( $\left.\log _{\text {tree age }}\right)$

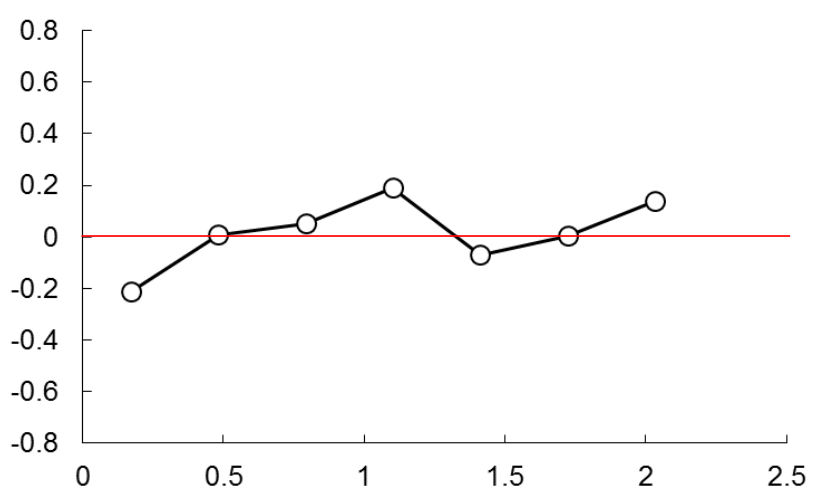

Distance class ( $\left.\log _{\text {tree age }}\right)$ 


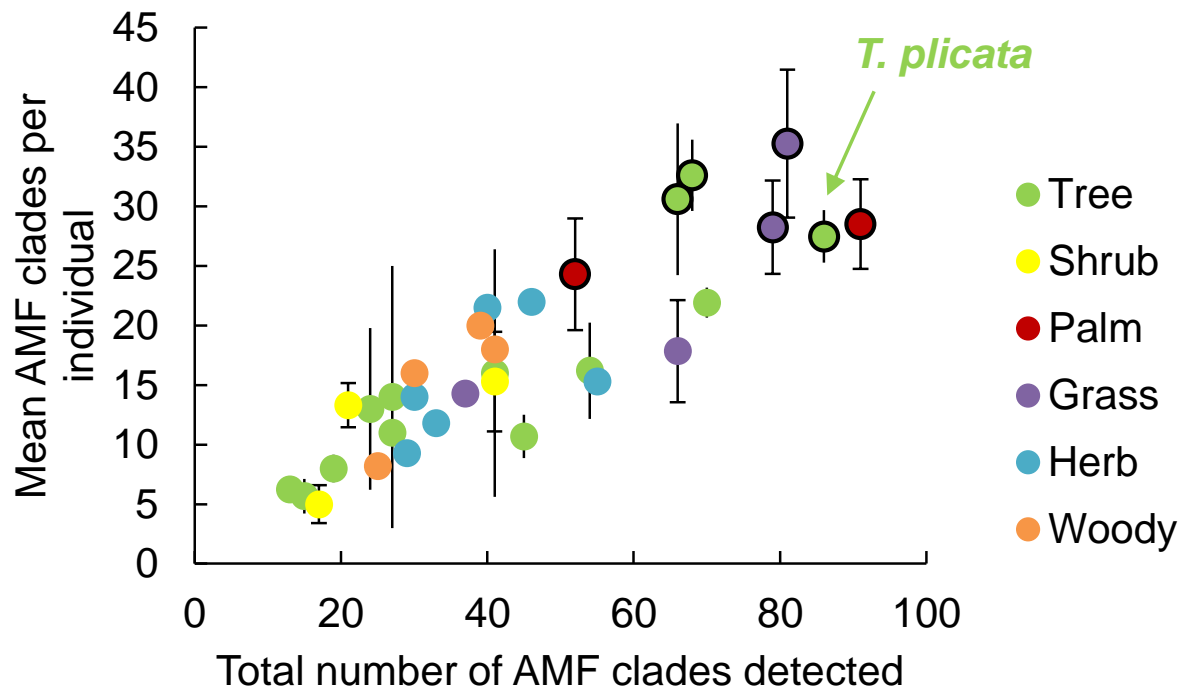

